University of East London Institutional Repository: http://roar.uel.ac.uk

This paper is the author's manuscript copy of a book chapter and is made available online in accordance with publisher policies. Please scroll down to view the document itself. Please refer to the repository record for this item and our policy information available from the repository home page for further information.

The final version is available to purchase from the publisher's website.

Author(s): Rustin, Michael

Article Title: What do child psychotherapists know?

Year of publication: 2009

Citation: Rustin, M. (2009) 'What do child psychotherapists know?' Published in Midgley, N., Anderson, J., Nesic-Vuckovic, T. Urwin, C. (eds) Child Psychotherapy and Research: New Approaches, Emerging Findings, Routledge 2009, pp 35-50.

Published version available to purchase from:

http://www.routledge.com/books

ISBN: 978-0-415-42202-4

Publisher statement:

http://www.tandf.co.uk/journals/copyright.asp 
Published in Child Psychotherapy and Research: New Approaches, Emerging Findings, ed. Nick Midgley, Jan Anderson, Tanyja Nesic-Vuckovic and Cathy Urwin. Routledge (2009), pp 35-50.

\section{What do child psychotherapists know?}

\section{Michael Rustin}

In the decades after the death of Freud in 1939, the psychoanalytic tradition in Britain was substantially shaped by child analysis. Melanie Klein's discoveries emerged from psychoanalytic practice with children, which was based on 'play technique'. Some of Donald Winnicott's most important ideas were developed through work with children, and through study of the relationships between mothers and babies. Although the main clinical context for Bion's discoveries was the analysis of adult psychotic patients, among his resources in undertaking these investigations were the theories of paranoidschizoid and depressive mental functioning and projective identification, from which his account of the origins of the mental apparatus and of the containercontained relation emerged. There are notable parallels between Esther Bick's understanding of the acute anxieties of infancy (the fear of 'falling to pieces') and Bion's understanding of the fragmented states of mind occurring in psychotic patients. Anna Freud was as dedicated as Melanie Klein to the analysis of children, and many of her principal contributions to psychoanalysis were based on this. Thus the theoretical advances of the 1940s and 1950s in the British psychoanalytic tradition could not have occurred without the priority given to the psychoanalysis of children, and the corpus of ideas and techniques with which British analysts now work can scarcely be imagined without that contribution.

This should hardly be a surprise. Psychoanalysis is a theory of development, explaining the psychic pain and malfunctions which are its clinical object through understandings of what happens, internally and externally, in the early life of children. Most psychoanalysts believe that they have access, 
through the psychoanalysis of adults to the 'child in the adult' - that is to the unconscious beliefs and habits of mind formed in response to early experiences. It is held that these early dispositions of mind, and sometimes memories, are re-lived within the transference setting, and are understood through the counter-transferences of analysts. Freud thought of psychoanalysis in part by analogy with archaeology, as the excavation of buried layers of consciousness. But whatever the possibilities of gaining access to unconscious states of mind through analysis in adulthood, the psychoanalysis of children gave new and direct access to these early formations of mind.

In the past few decades, the analysis of children by psychoanalysts has, rather sadly, declined. In its place, the new profession of psychoanalytic child psychotherapists has grown up, to a size comparable with that of the British Psychoanalytical Society. There has been a great deal of co-operation between the psychoanalysts and the child psychotherapists, and child psychotherapy remains closely linked to the mainstream psychoanalytic tradition in Britain . But the migration of child analysis to child psychotherapy largely being undertaken within public mental health services for children and families, ${ }^{1}$ means that if we want to understand the generation of new knowledge in child analysis in Britain today, it is to child psychotherapy we must look.

\section{The Generation of Knowledge in Psychoanalysis}

In this chapter I am going to review some major achievements of the clinical research programme of child psychotherapy, before considering the encounter between psychoanalysis and 'mainstream' social scientific research methods which is a major topic of this book. But before doing this, it is necessary to say something about scientific methods more broadly.

\footnotetext{
${ }^{1}$ In the NHS child psychotherapists mostly see patients on a once-weekly basis, though intensive cases provide a major element of their training. It does often prove possible to do
} 
Since its invention as a new paradigm by Sigmund Freud, psychoanalysis has evolved as a highly productive research programme. Its primary research method has been clinical, its main laboratory has been the consulting room. Its theories and classifications (of developmental patterns, psychic structures, psychopathologies) have continued to develop, as psychoanalysts have revised and extended their theories to take account of new clinical evidence. The main purpose of this gathering of knowledge has been to inform clinicians in their practice.

It is normal in the history of the sciences for techniques of investigation to evolve in response to the nature of particular objects of research. Consider, for example, the differences between

- the mathematical sciences, which study 'virtual objects'.

- physics, whose commitment is to discovering uniform and universal laws about the elementary properties of nature.

- the biological sciences, much of whose agenda has until recent years been the description and classification of the diversity of species, unified by the theory of natural selection which is most informative in its application to particular species and eco-systems.

- the human sciences, which have to take account not only of the diversity of human kind, but also of the self-understanding and selftransformative properties of human subjects. The human sciences for these latter reasons have had to acknowledge limitations to the empirical scope of the theories they devise - they continually trace a moving target. A further complication of the human sciences, , is that their perspectives have usually been shaped by commitments of value, which sustain different research agendas, as human scientists seek to understand the conditions of possibility of this or that imaginable world. It is not only the 'immaturity' of the human sciences (including psychoanalysis) which have led to their disunity, but the

transference-based psychoanalytic work within what some might see as unpromising 
differences of moral viewpoint which continue to inform and divide them.

There is thus not one science, but many (Galison and Stump 1996).

Psychoanalysis has too often been negatively judged by criteria deriving from a philosophy of science whose ideal typical model was the physical science of the early $20^{\text {th }}$ century ${ }^{2}$, and from a positivist psychological tradition which reduced the complexity of its human subjects in order to follow its preferred methods of experiment and measurement. I have argued elsewhere that the specificity of method of psychoanalysis is appropriate to its object of study.

In the history of psychoanalysis, and more recently in child psychotherapy, knowledge has been advanced through the juxtaposition of new clinical findings, with established classifications, and theories. Newly recognised phenomena have been designated by new concepts. (Rustin 2002a, 2007, Hughes 2004). Taxonomies (for example of psychopathologies) have evolved to become more differentiated and fine-grained in response to clinical experience. T.S. Kuhn (2000) in The Road since Structure (chapter 4) described the proliferation of ideas within a paradigm which accompanied the 'puzzle-solving' of normal science as a kind of 'speciation', comparing this with the evolution of living species. This is a useful metaphor for understanding the proliferation of concepts and theories in psychoanalysis.

There is a tension in psychoanalysis between the wish to understand particular experiences and persons, and the goal of discovering uniformities and laws governing all psychic phenomena. If one is too taken up with individuals, there will be no concepts or theories to confer meaning. But if

\footnotetext{
circumstances.

2 David Stove (1982) suggested that Popper's model of 'falsifiability', which rejects the inductive principle that positive empirical evidence provides good reasons for belief in a theory, and thus proposes a rigorous scepticism, was a response to the upheaval to Newtonian science brought about by Einstein. Popper wished to ensure that no-one would ever again be deceived by certainty. Permanent scientific revolution would henceforth rule. One can see how Kuhn's theory of scientific revolutions gave this programme a historical perspective.
} 
one is too committed to abstractions, one loses sight of individual persons, making descriptions lifeless and without sense to patients themselves. When Bion urged that analysts 'eschew memory and desire', and be open to an experience of 'unknowing', he was emphasising the dangers that the dead hand of theory and preconception could bring to the analytic encounter. But he remained deeply committed to theoretical notations, and attempted their systematic classification in the formulation of his 'grid'. Like complexity theorists who have defined 'the edge of chaos' as the primary location of creativity and innovation, Bion insisted that psychoanalysts need to expose themselves to the disorientation which inevitably follows experiences of the particular, but also remain attentive to the explanatory power that psychoanalytic thinking embodies.

Psychoanalysis and child psychotherapy are shaped as vocations by their encounter with the individuality of their patients understood as whole persons. In psychoanalytic work, diagnostic labels for patients, although to a degree necessary, are secondary to understandings which respect individual selfhood and subject's desire for self-understanding. One can think of psychoanalytic concepts as constituting a 'virtual library' of resources for naming and explaining clinical phenomena. The task for therapist and supervisor is to decide on the most useful correspondences between new clinical phenomena, and the pre-existing ideas which can give them meaning, either by 'vertical' deduction from more abstract principles (e.g. the Oedipus Complex) or by 'horizontal' analogy with other known cases. Sometimes clinicians come to recognise that new juxtapositions and combinations of ideas are called for by the need to give a difficult clinical experience a shape and a name.

Most of the time, most psychoanalysts and child psychotherapists work to bring together experience and the lexicons of understanding already established. For clinical purposes, to understand the patient and the ongoing process of her psychotherapy, with some coherent reference to the formulations of the literature, is difficult in itself. The practice of 'normal 
science' or 'puzzle solving' in psychoanalysis involves at a basic level understanding individual patients. It is because of this commitment of psychoanalysis to the complexity of its individual subjects that its findings have been best represented in represented in case-studies, and in monographs on different sub-species of pathology or development, rather than in the codified style of a textbook.

But sometimes, psychoanalysts have not been content with trying to make sense of individual patients within the terms of already-established ideas. Under pressure of difficulties in understanding recalcitrant clinical phenomena, analysts have reflected on the adequacy of the concepts available to them, and have proposed new conceptions. The development of theories, taxonomies and techniques in psychoanalysis takes place in response to encounters with recalcitrant 'facts; emergent theories then being subjected to later clinical test and trial. The development of psychoanalytic theory can thus be understand as the record of a continuing clinical research programme. Imaginative conjecture and deductive brilliance have had a major place - no one can doubt the theoretical capacities which Klein, Bion, Winnicott or Meltzer brought to exploring the potentialities of ideas. But theories have usually been barren in this field unless they have rapidly found a clinical referent, or some other application to experience.

During most of the history of psychoanalysis, this development has proceeded according to criteria which have been given little explicit specification.

Psychoanalysis has been a field of 'tacit knowledge', in Michael Polanyi's (1958) terms, of 'craft practices' and intellectual sensibilities, fine-honed and shared within the knowledge-community of the profession, but subject to little formal clarification at 'meta-levels' of justification. The length and intensity of training of psychoanalysts, and the meticulous routines (observation, supervision, personal analysis) of which its learning processes are made up, are designed to achieve a consistent quality of practice, internalised as professional 'second nature'. (Rustin 2003) 
In recent years, this situation has begun to change, under two opposite pressures. On the one hand implicit claims to professional competence do not fare well in the culture of 'evidence-based medicine' and psychotherapists have been placed under pressure to provide empirical justification of their knowledge and practice. On the other hand, former orthodoxies in the philosophy of science have been challenged by developments in the history and sociology of science, and there has been greater understanding of the diversity of actual methods. Psychoanalysts have come to see that their own procedures can be made more accountable without compromising the essence of psychoanalytic practice. Academic accreditation of psychoanalytic trainings has also made a difference, since it has demanded explicit justification of methodologies. A vigorous debate about the role of research in psychoanalysis has thus begun, to which of course this book is a contribution.

One lesson which can be learned from the recent history and sociology of science, for example in the work of Kuhn $(1962,2000)$ and Latour (1983, $1987,1988)$ is that descriptive questions concerning what scientists do, and how they do it, are more illuminating than prescriptive judgements which seek to demarcate 'good' from 'bad' scientific practice. Thus the best starting point for considering the role of research in child psychotherapy is to review the contributions to knowledge which have been achieved by this discipline since its inception in 1948, and to explore how these have come about. Some fields of discovery stand out as outstanding examples in a wide field..

\section{Clinical Research in Child Psychotherapy}

Consider first, what has been learned over the past thirty years about psychoanalytic work with severely deprived children. since the publication of Gianna Williams' seminal 1974 paper, Doubly Deprived, Here was a population of children (and their families) which was earlier thought untreatable by psychoanalytic methods. At an earlier stage of child analysis, as Margaret Rustin has recently pointed out, most patients were recruited from the middle-class professional culture of psychoanalysis itself, and were given analytic treatment in response to difficulties far less severe than those 
which are encountered routinely by contemporary CAMHS services. But the embryo profession of child psychotherapy, embedded as it was in family mental health services, began to respond to the needs of patients drawn from families in the care of social services, who had experienced often catastrophic breakdowns. These children might, by the time of referral, be in children's homes or later in foster- or adoptive-placements which were proving extremely difficult for all concerned.

Gianna Williams defined the relevance of a psychoanalytic understanding to this situation, in her recognition that 'deprivation' in the lives of such children was not merely 'external', in a child's loss of real parents, but also had another dimension, in the damage to a child's 'internal parents' effected by traumatic experiences or abandonment. Unless this internal damage was addressed it was likely that attempts to achieve external reparation through providing a new family for a child would encounter extreme difficulties. Children in such placements were often found to test their new foster-carers to the point of despair, as they lived out the damaged object-relationships of their internal worlds, in the vulnerable settings of their new homes.

The child psychotherapists' method of investigating this situation was largely clinical. Psychotherapists tried to work therapeutically with such patients, adapting their technique accordingly. They developed ideas which enabled them to understand their clinical experience. They practised a co-operative method of work, 'the practitioners' workshop' (Rustin 1991) as a way of thinking together, and supporting each other and their trainees in coping with the extreme stress of this work. Mary Boston and Rolene Szur's edited collection, Psychotherapy with Severely Deprived Children (1983) was the outcome of such a workshop. Informally, clinical workshops like this enable practitioners to explore and test out ideas with many similar cases, 
overcoming some of the difficulty of clinicians' work with single cases, and making possible a measure of generalisation. ${ }^{3}$

The most significant clinical evidence arose from the severity of the impact of these patients on their therapists. The patients' hostility, desperation, and rejection was often overwhelming, and difficult to manage both personally and therapeutically. Theoretically essential was attention to the countertransference, and to what Betty Joseph has described as the 'total transference situation'. (Joseph 1989, 1994). Only if what was being experienced by the therapist was understood at least in part as a projection by the child patient of his own unbearable states of mind, and as communications to the therapist of what it felt like to be such a child, did the situation become comprehensible, and one with which analytic work became possible.

Bion's concept of the container-contained relation was also central to this exploration. Therapists found that their own capacity, and that of the therapeutic setting, to contain the violence and anxiety of their patients was stretched to the limit, but they also learned that such containment was the precondition of any analytic work. They came to understand that the origin of the patients' difficulty often lay in extreme failures of containment during their earlier history. Gianna Williams (1997) elaborated her understanding of the container-contained relation, to take account of its different possible modalities. In contrast to the form of facilitating containment dominated by the role of Bion's 'alpha function' (the 'metabolisation' of psychic experience, in particular unconscious anxiety, through 'reverie') she evolved the concept of 'omega function' to characterise its opposite, namely the intrusive or toxic projection into others (especially infants) of states of anxiety found unbearable by parental figures. (See also Selma Fraiburg 1975 on intrusive kinds of projection into infants.)

\footnotetext{
${ }^{3}$ The Anna Freud Centre also established clinical workshops at an early stage, which gave rise to some important papers, for example Rosenfeld and Sprince (1963).
} 
Williams extended the relevance of this reversal of containment to the field of eating disorders in children and adolescents.(Williams 1997a, 1997b). She and her colleagues in another clinical workshop setting have been able to develop understanding of the rejection of food, and of other life-giving intakes, as unconscious responses to early experiences in which infants experienced their mothers as intrusive rather than containing, and where feeding was felt to be emotionally toxic. The clinical evidence for this hypothesis also came from the dynamics of the transference and the countertransference. Patients were found to attack the meaning and care offered within the psychotherapy setting, and this was understood as a representation of the patients' broader refusal of nurturing and feeding relationships.

The psychoanalytic understanding of severely deprived children has been considerably developed since the publication of Williams' original paper and Boston's and Szur's book. Some writers (Kenrick 2005, Rustin 2001) have explored issues of technique, describing the violent attacks on therapist and setting made by patients, and techniques which they have adopted to cope with these. This writing has enabled clinicians to see parallels with their own experience, and feel less overburdened by a sense of failure. It has enabled helped therapists and their supervisors to anticipate difficult situations.

Different aspects of the states of mind of such patients have been elaborated. Hamish Canham (1999) described the characteristic timelessness of the world of such patients, and the significance of establishing a sense of time. In another paper Canham (2004) described the extreme physicality of such a patient, and Juliet Hopkins (2000) described difficulties in the management of sessions, and established important equivalences between the understandings of these phenomena within psychoanalysis and attachment theory. In the related field of adoption, Margaret Rustin (1999) drew attention to the 'multiple families in mind' of adopted children (their biological parents, adoptive parents, and parents-in-phantasy), and the reciprocal issue for adoptive parents of the biological children they do not have, but who may nevertheless be present in their minds. This literature is psychoanalytic in its 
exploration of the dimension of the problem of these children which is located in their inner world.

A field of 'clinical research' of this kind evolves as a 'branching tree' of classifications. Here we can add the particularity of sexual abuse and sexual enactment as an aspect of deprivation, and its possible impact in the clinical situation (Lanyado 1991, Ironside 1995) and the significance of the experience of the oedipus complex, as another developmental moment, and link with classical psychoanalytic theory. (Anderson 2003, Bartram 2003, Canham 2003) It has more recently become recognised that the management or mis-management of children with difficulties within the care system is the source of additional problems of its own - a kind of iatrogenic mental illness - and child psychotherapists have investigated the experiences of transition, in which a care-system seems to lose capacity to hold the children in mind. (Hindle 2000, Hunter 2001 Philps 2003). Margaret Rustin explored this situation in a different way in her commentary on the difficulties of the care-system in responding to the situation of Victoria Climbié, difficulties which led to her death (Rustin 2005).

A second leading example of clinical research in child psychotherapy has been in the field of autism and its associated disorders. We can see here a succession of clinical and theoretical studies undertaken by child psychotherapists, (Alvarez 1992, Alvarez and Reid 1999, Haag 2000, Houzel 2004, Rhode 1994, Tustin 1992) though in cooperation with psychoanalysts such as Donald Meltzer (Meltzer et al. 1975), and in dialogue with experimental psychologists working in child study laboratories, who have mapped out aspects of behaviour previously inaccessible to study. Since almost by definition, children suffering from autism are unavailable to a major degree to psychoanalytic interventions based on language and interpretation, clinical investigators of autistic phenomena have made extensive use of the methods of psychoanalytic infant observation which were developed initially by Esther Bick (Briggs 2003) but then became the pre-clinical foundation of child psychotherapy training. The close observation of the 'state of being' of autistic patients, in their relation to their own bodies, to physical objects and 
sensations, and to the body and person of their therapists, has been one way in which child psychotherapists have sought to understand the origin and meaning of autistic disorders.

It is often the case that psychoanalytic understanding has been advanced not by the investigation of normal or average patterns of development, but by the need to understand those patterns which lie at the furthest extremes of abnormality - autistic or psychotic states, for example. Autism is a topic of broad significance for psychoanalysis because it reflects a disturbance of development which seems to have its onset in very early bodily and mental experience.

Links between the understanding of autism, and the psychoanalytic theory of early development, were very clearly set out in what Frances Tustin said would be her last published article (1994) in which she described the view of the origin of narcissism she had reached as a consequence of her studies of autism, in contrast to her earlier view. In this paper, she rejected the idea that narcissism was, as Freud had written, an original condition from which individuals later emerged. She wrote that narcissism - the delusion of a selfsufficient self, the denial of relationship with an object- is a defence against a separation from mother which is experienced as traumatic and terrifying. In normal development, the baby is from the beginning in a reciprocal relationship with the breast, and mother, though this relationship becomes more complex and differentiated as the baby develops. It is this sense of relatedness and safe dependence - containment has become a usual term for it - which sustains the baby's sense of himself or herself, as capable of surviving even when not in close contact with its mother.

Psychoanalytic investigators of autism have clarified that the developmental tasks which babies have to cope with in their first weeks of life have from the start a mental as well as a physical aspect. It was difficult to give a credible account of this view when psychoanalysts had seemed to be ascribing to tiny infants more complex 'inner worlds' than it seemed conceivable that they could have. Some of the argument between sensitive observers of infant 
development such as Daniel Stern or Colwyn Trevarthen, and child psychotherapists focused on the implausibility, according to the former, of assigning states of phantasy to infants at a stage when they seemed not to have the mental resources which made phantasy possible.

But the focus within the psychoanalytic study of autism on those very early states of mind which are concerned with basic bodily and psychic integration have brought some progress in understanding early development from a psychoanalytic perspective. The fear of 'falling to pieces' or liquifying, described by Esther Bick (1968) and Sydney Klein (1980) is more primitive than the anxieties about 'objects' posited by the theory of the paranoidschizoid position. Until some sense of coherence and unity of the self is achieved, there is no possibility of distinguishing self from other, the loved from the hated object. Autism is a defence against the anxiety of disintegration and fragmentation which follows upon the failure of the primary object to support the self in its earliest experiences of separation. Of course this may be the outcome not of actual deficit in the capacity of the primary object, but may rather be the consequence of the initial fragility and vulnerability of the infant, perhaps of genetic origin, or as a consequence of prematurity or illness in mother or infant. But subjectively, this fragile infant's experience is that any separation, and thus exploration of the qualities of its object, is unbearable, and is experienced as catastrophic.

The observational and clinical research programme of investigators of autism has been exploring many of the different sensory modalities of the infant's earliest experiences, to see the particular part each of these has in the development of autistic defences. Significantly, much of this work has been undertaken with the support of clinical workshops. In Europe, Susanne Maiello (1995) has studied the primary experience of 'the sound object', tracing this back to pre-natal experience, and examining its role as an element in the relationship of infant and mother. Genevieve Haag (2000) has developed an understanding of the normal experience of the body as possessing a backbone, and a symmetrical organisation of left and right sides, observing the disturbance of this symmetrical unity in autistic 
development. These observers of autistic children have noted their extreme preoccupation with bodily surfaces and orifices, preoccupation with surfaces providing a kind of contact with or relation to the world in the absence of a sense of that world as three-dimensional, and that persons and things have interiors and exteriors. Maria Rhode (2004) has explored the infant's experience of the mouth in a situation where there is no tolerance of separation from mother.

These ideas have had consequences for clinical technique. Since autistic children's primary form of contact with the world, and with others, may be through adhesion to or exploration of such physical surfaces, it has been found necessary to attend closely to children's physical engagement with the therapist and the setting, seeking out kinds of responsiveness to them which enhances their sense of trust and agency, as the precondition for more complex communications. Anne Alvarez (1992) has described her active technique of 'reclamation', with its aim of enhancing her patient's expressive and communicative repertoire in order to get a live relationship started.

The conjecture underlying this work is that the emergence of a capacity for experience of the self as separate from its object, and of the body and mind held together with joined-up-ness and intentionality, is a primary developmental task, which depends for its fulfilment on the interaction between a receptive and responsive mother (or equivalent) and an objectseeking baby. If the containing relationship is absent, the infant may turn away from the object, and seek to sustain itself from its own resources. If the infant lacks the innate capacities for object-seeking, there may be similarly devastating consequences. Deprived of containment, or thrown on to its own self-sustaining resources, infants will be unable to sustain the task of creating a coherent body and mind, and will evolve instead substitute modes of bodily survival and continuity, which become barriers to normal development and relationship. ${ }^{4}$

\footnotetext{
${ }^{4}$ I have been put in mind of these developmental issues by informal observations of my baby granddaughter, aged 11 months at the time of writing. What struck me, during her first few months, was the extent to which she seemed preoccupied with getting to know and
} 
The substantial programme of clinical and observational study of children with these difficulties has given rise to theoretical formulations, setting out the implications of these findings for the understanding of psychic development. One useful theorisation of this kind has been set out by Thomas Ogden (1989), in his concept of the 'contiguous-autistic position' which he holds to be a normal stage of development prior to the onset of the paranoid-schizoid and depressive positions theorised by Melanie Klein. Ogden draws in his formulation on the writings of Bick, Bion, Meltzer Tustin and Winnicott, as well as on his own clinical work with adult sufferers from autism. ${ }^{5}$

I have given examples of fields child psychotherapy where substantial new knowledge has been generated in the consulting room, and made available to practitioners in their literature as it has emerged. One could add many others. For example, the study of autism has led on to the investigation of the related disorder named Asperger's Syndrome. (Rhode and Klauber 2004).

understand her own body, and the feelings it gave rise to. 'What is this sensation?' she seemed to be asking herself, the sensation in question often seeming to be located somewhere in her tummy. Clutching her foot or her hand, 'what is this, what does it do, what can I get it to do?' 'Why when I go over this way, do I come to a stop, or roll back again? Much of the time, at this stage, baby granddaughter did not seem to have much space in her mind for outside objects, unless they could be put her in mouth, her mother excepted.

But a few months later, how different. Hands can grasp things which can be banged! One can crawl at great speed. One can climb up flights of stairs, bashing down on the surface of the next step up, perhaps to see if it will bear weight. One can pull objects apart, and try to put them together again. Things and places are endlessly interesting, especially if there is someone around to share the interest. And people! 'Here's Mummy back again, how lovely!' ('Oh but I missed her, I now realise.) 'Here's grandma, I like grandma.' 'And here is the cat, eeeeek ! What excitement to see her again, and crawl along beside her, watch her eating, pull her fur!'

What a difference, in other words, between the time when baby is mainly getting to know the boundaries and elementary capacities of herself and her own body and its sensations, with all the concentration this requires, and what happens once something of this has been achieved, and when energies are freed to look outwards, and start experimenting upon the world. It seems to me that the disorders and disruptions of autistic development may take place at that first stage, before exploration of the world becomes possible, or that they may reawaken this primary experience of disintegration and integration.

\footnotetext{
${ }^{5}$ Note that the broader theoretical connections of these ideas have so far been elaborated more by psychoanalysts than by child psychotherapists. It would incidentally strengthen the clinical research tradition of child psychotherapy if there were more frequent reviews in its literature of its various fields of work, updating and synthesising their findings.
} 
Parallel to the study of autistic disorders in child psychotherapy has been the clinical investigation of more florid psychotic states, with the different technical and explanatory issues which they raise (Rustin, Rhode, Dubinsky, Dubinsky 1997.)

The close attention to the anxieties attached to early infancy has led to investigation of the experiences of infants born prematurely, or looked after in neo-natal units, throwing light on the traumatic nature of their under-protected situation, and suggesting ways in which the quality of care could be brought closer to that of an infant cared for by its mother. A further extension of this attentiveness to bodily and emotional anxiety, in the context of the care of children in hospital, has led to sensitive observational studies which have shown what difference can be achieved if nurses can learn to 'be' with children who have to suffer intrusive treatments, and enable them to feel that their feelings are understood, and that they need not be deprived of all choice and agency in their painful situation. (Hall 2003/4). ${ }^{6}$ A related field of investigation is 'parent-infant work', in which difficulties in the early relationships between mothers and babies are attended to by creating a therapeutic space in which mothers are able to share some of their fears, and learn that they can understand what is happening to them and their baby. Once mothers' extreme anxieties are relieved, and they become freer to observe and reflect, babies also become less anxious. Mothers and babies may turn towards each other, and development can begin. Infant observation is proving to be a major addition to psychoanalytic methods of investigation and intervention, with applications to contexts beyond those of infancy.

\section{Questions of Method}

My contention is that the established tradition of clinical research in child psychotherapy, broadly following the methods of discovery of

\footnotetext{
${ }^{6}$ See also Pamela Sorensen's (2000) paper on 'transition facilitating behaviour, arising from her work in a neo-natal unit, and related to this, Didier Houzel's (1995) concept of 'precipitation anxiety'.
} 
psychoanalysis, has been productive in generating new knowledge. It has enhanced our understanding of child development and its various difficulties and disorders, and has evolved new clinical techniques in response to these. It has found new contexts of application for powerful psychoanalytical ideas such as those of projective identification, counter transference and the total transference situation - and shown the relevance of classical ideas, such as the Oedipal situation, to explaining hitherto unfamiliar disorders.

But some argue that this is insufficient. Psychoanalysts and psychotherapists have to move closer to the scientific mainstream if their findings are to have wider credibility. Nicholas Midgley $(2004,2006)$ has proposed that qualitative research methods developed in sociology and psychology may be useful in clinical research, and can lead to improvements in many of its procedures, in both the gathering and processing of data. He has rightly pointed out that child psychotherapists undertaking doctoral research projects are now making use of systematic qualitative methods, such as 'grounded theory', and the independent rating and interpretation of findings, to set their work on firmer ground. Some substantial projects, such as the Adolescent Depression Study undertaken by Judith Trowell, Maria Rhode, David Campbell and colleagues in Finland and Greece (Trowell et al 2003), have gone further in the formalisation of research methods. They have used standardised tests of mental health and well-being before, after, and in follow-ups of treatment; they have confined psychotherapy to a predetermined number of sessions; and they have audio-recorded therapy sessions to provide more reliable data. In addition, this study has compared courses of treatment of psychoanalytic child psychotherapy with systemic family therapy, thus establishing a comparative measure of outcome.

Such developments are to be welcomed. Research into the outcomes and effectiveness of treatment, is particularly important and urgent, since in today's 'evidence-based' culture of health care commissioners demand data to substantiate claims for the value of psychotherapy, and are sometimes unwilling to accept professional advice unsupported by statistical evidence. Outcome studies are one form of research in which systematic quantitative 
techniques are essential, and where traditional clinical modes of discovery cannot suffice. $^{7}$

But the implied idea that psychoanalysts and psychotherapists have been methodologically naive, compared with the researchers from psychology, sociology and other human science disciplines, is not well-based. One of Nicholas Midgley's $(2004,2006)$ two valuable contributions to this debate, 'Between Scylla and Charybis: Incorporating qualitative approaches into child psychotherapy research', cited a three-phase chronology of psychoanalytic research proposed by John McLeod (2001). In the first of these, up to the 1950s, 'the main emphasis was on description and discovery, and the primary means of research was the single case-study.' In the second phase, from the 1950s onwards, 'consolidation and routinisation' gradually became dominant. The aim supposedly shifted from 'discovery to verification, with the aim of establishing a firm professional basis to our work.' In the third and current phase, which Midgley sees as a time of 'uncertainty and opportunity', there are pressures to develop an 'evidence-base' using 'scientific' empirical measures, but there are also new opportunities to bring sophisticated qualitative methods to bear on psychoanalytic questions.

Although it is true that the turn to qualitative methods in the social sciences is beneficial for psychoanalysis, McLeod's historical underpinning of this argument is quite misleading. The reality is that psychoanalysts have continued to make major discoveries, using clinical case-study methods, throughout the decades from the 1950s to the present. These years saw the publications of analysts such as Segal, Bion, Rosenfeld, Joseph, O'Shaughnessy, Britton, Sandler, Steiner, Ogden and Bollas, as well as those of the child psychotherapists referred to above. The lexicon of ideas and theories which is employed by most child psychotherapists today would not exist without this record of clinical research. For example, one of the

\footnotetext{
${ }^{7}$ Sometimes however this professional pressure leads to research into outcomes being seen as virtually synonomous with research itself. See for example Hodges (1999) in Lanyado and Horne (1999).
} 
crucial ideas now being operationalised in a quantitative empirical form by Peter Fonagy, Anthony Bateman and others, that of mentalisation, seems to have as one of its main origins Bion's theory of the mind.

What also goes unnoticed in the undervaluation of the clinical psychoanalytic tradition are the substantive reflections made by analysts and child psychotherapists on their own methods of research (though they do not usually describe it in these terms.) Bion's investigation of psychotic states of mind required him to recognise as 'data' phenomena that had been hitherto unintelligible to psychoanalysts. His own discussion of the 'selected fact' and the mode of seeing coherence in these phenomena drew on the mathematical ideas of Poincaré, and anticipated the subsequent development of complexity theory.(Rustin 2002b). In a similar way, Betty Joseph's understanding of the 'total transference situation' (Joseph 1989, 1998) required her to reconsider the meaning of the facts of the psychoanalytic encounter, enhancing the level of detail in which clinical phenomena were perceived, as if a new instrument had appeared which could find meaning in sequence, timing, interaction and silences in clinical interactions. The fundamental idea of projective identification (Sandler 1988) required psychotherapists to think of patients' communications as actions or enactments, rather than merely as representations of hidden levels of meaning. Developments in the philosophy of language which had led to the acknowledgement of the 'performative' aspects of 'speech acts' thus had their equivalent in psychoanalytic practice, probably not under the direct influence of the philosophers, but as a parallel discovery. Meltzer's (1978) commitment to a 'hermeneutic' and vehemently 'non-causal view of psychoanalytic theory, in his account of the Freud-Klein-Bion tradition, also echoed the 'interpretative turn' which was taking place in those years in philosophy and the social sciences. Counter-transference is a methodological as well as a clinical resource, since it identifies a new source of information. It is surely also clear that the discoveries of child psychotherapists described above have depended on new ways of perceiving and understanding clinical phenomena, whether through the counter-transference or through fine-grained observation of links between body and mind. 
Criticism of psychoanalysis for blurring the boundaries between facts and theoretical inferences drawn from them was anticipated in psychoanalytic and child psychotherapy practice before it became an issue for research methodologists. The tradition of psychoanalytic infant observation was founded in the 1940s on the discipline of detailed, literal, descriptive report, precisely to instil an empirical habit of mind among trainee psychotherapists. Closely Observed Infants, the first book to systematically set out this method, in 1987 made a commitment to the distinction between data and theory absolutely plain, as did Meltzer (1967 chapter 4). What proved decisive in 'The Controversial Discussions' in the early 1940s, in gaining support for some of Melanie Klein's ideas, was the evidence provided by her new method of child analysis. It was primarily a new kind of clinical fact that convinced the uncommitted members of the professional community. (King and Steiner 1991).

The fact is that discovery in psychoanalysis has always depended on a selfcritical attitude to clinical data. Psychoanalytic theories assign meaning and connectedness to specified kinds of facts; without attention to the nature of these facts and how they are apprehended, there could be no valid or useful theories. The $75^{\text {th }}$ Anniversary Special Issue (1994) of the International Journal of Psychoanalysis on clinical facts was an important milestone in psychoanalytic engagement with these issues. (Tuckett 1994a and b). Psychoanalysts who began their work in other disciplines, such as the former sociologists Elizabeth Spillius, David Tuckett, and Susan Budd, have brought to these questions familiarity with wider debates on methods.

Psychologists such as Peter Fonagy have brought another disciplinary crossfertilisation. (Fonagy 2001). Glaser and Strauss's grounded theory, which came from sociology but which has been found so useful by psychoanalytic researchers, consists of a method of moving inductively between qualitative data and concepts which is very close to the way in which in clinical practice and supervision meaning is expected to emerge from study of the material, while holding theoretical preconceptions at a distance. 
This is not to question the relevance to child psychotherapy of the range of qualitative methods which been developing in recent years, in what has been in fact a veritable 'methodological boom' in the social sciences. ${ }^{8}$ Child psychotherapists often feel anxious about their own lack of expertise about research methods, and they find that psychoanalytic ideas are attacked as 'unscientific'. While they need to respect their own tradition, and understand its contributions to knowledge, they can and should use more systematic and transparent research methods. They will find that they provide valuable resources for their own investigations.

But there are two major complications which need to be kept in mind as child psychotherapists draw upon research methods whose original application has usually been outside the field of psychoanalysis. The first of these is that an 'object' of investigation is often related to its method of inquiry in quite definite and determinate ways. Ontologies - conceptions of what is - are usually associated in a logical way to epistemologies - conceptions of how one knows something. Research methods are not all-purpose tools, fit to be bolted-on to any field of study. One would expect that psychoanalysis with its particular object of knowledge, namely unconscious mental process, would come to have particular methods of research, designed specifically for the understanding of this object and its qualities. This is indeed the case.

A related point is that forms of relevant knowledge are specific to their audiences or users, as well as to their objects. Mental health commissioners quite reasonably need to know about the effectiveness of treatments which can be delivered in relatively standard and predictable ways. How else can they make rational judgements about how best to use their resources?

\footnotetext{
${ }^{8}$ Although interest in research methodology has followed naturally on the expansion of research itself, the current insistence on prescribed methodological training for all researchers in the social sciences, sanctioned by the funding system, is not an unqualified good. It also reflects a culture of credentialisation and regulation in academic and professional life, designed to exclude as well as to enable. This is seen also in the meticulous rules concerning 'ethical permission' for research, even in some places for undergraduate dissertations where formerly the judgement ot tutors was thought an adequate safeguard of practice.
} 
Particular kinds of knowledge need to be gathered to inform such decisionmaking. But therapeutic clinicians, expecting to work with an individual patient, though they should know about significant research on different categories of patient (looked-after children for example) and on treatment outcomes, need a more specialised kind of knowledge as well. This takes the form of a virtual library of relevant conceptions, theories, and cases, so that when the 'unknown' of the patient or the therapeutic session appears, they have to hand the discriminations with which to think about them. Such primary knowledge makes possible the treatment outcomes which justify a mental health service, but it has a level of delicacy and specificity which managers and policy-makers can best leave to the practitioners.

The fact is that most of the understanding produced hitherto in the practice of psychoanalysis has so far been of a kind relevant to clinicians, and its intended users have mainly been psychoanalysts and psychotherapists. The 'speciation' of concepts, theories, classifications and techniques in complexity of thinking which matches that of the patients, and which has evolved with their presenting problems as a consequence of many kinds of change.

It follows that while exploration of the range of research methodologies now so evidently on the market in the human sciences should be pursued vigorously by child psychotherapists, the best research outcomes are unlikely to be achieved by treating research methods merely as bolt-on toolkits, needed as remedies for endemic psychoanalytic backwardness. What is required, as always in good research, is the interrogation of available methods to see how far they can provide answers to new research questions. The subtleties of the psychoanalytic and child psychotherapeutic tradition of inquiry, described above, and its rich resources of theory, need to be brought into dialogue with research techniques developed in other contexts. Innovation, when it occurs, usually has a methodological as well as a substantive dimension. Such hybridisation has already been taking place in psychotherapist researchers' use of 'grounded theory', who, contrary to Glaser and Strauss's original prescription of a theory-free inductive approach, 
have usually chosen to work within a psychoanalytic frame of reference from the start, while remaining open to new conjectures informed by it. ${ }^{9}$

There are interesting questions to be addressed in these exchanges. For example, can the procedures adopted to carry out 'outcome studies' not only measure treatment effectiveness, but also throw light on the underlying psychological conditions of patients, and on optimal techniques of treatment? Or will traditional psychoanalytic methods, albeit somewhat up-scaled through multiple and comparative case-studies and made more accountable in their analysis of data, retain their comparative advantage as the best ways of learning about unconscious mental life and the therapeutic process? ${ }^{10}$

There is much to be learned from the participation of psychoanalysts and child psychotherapists in this growing debate about methods of research.

\footnotetext{
${ }^{9}$ On the uses of grounded theory in psychoanalysis, see Anderson (2006).

${ }^{10}$ Such studies may demonstrate not only that psychoanalytic psychotherapy 'works', but also that it works because of the use for example of the transference, the counter-transference, or the negative transference. Such demonstrations of the validity of core psychoanalytic ideas
} 


\section{References}

Alvarez, A. (1992 Live Company: Psychoanalytic Psychotherapy with Autistic, Borderline Deprived and Abused Children. London: Routledge.

Alvarez, A. (2006) 'Some questions concerning states of fragmentation: unintegration, under-integration, disintegration, and the nature of early integrations.' Journal of Child Psychotherapy 32 (2) August 153-180.

Alvarez, A. and Reid, S. (1999) Autism and Personality: Findings from the Tavistock Autism Workshop. London: Routledge.

Anderson, J. (2003) The mythic significance of risk-taking, dangerous behaviour. Journal of Child Psychotherapy 29 (1) April 75-92.

Anderson, J. (2006) 'Well-suited partners: psychoanalytic research and grounded theory.' Journal of Child Psychotherapy 32 (3) December 329-348.

Bartram, B. (2003) 'Some Oedipal problems in work with adopted children and their parents.' Journal of Child Psychotherapy 29 (1) April 21-36.

Bick, E. (1968) 'The Experience of the Skin in Early Object Relations', International Journal of Psychoanalysis, 49, 484-486.

Boston M. and Szur, R. (eds) (1983) Psychotherapy with Severely Deprived Children London: Routledge.

Briggs, A. (ed) (2002) Surviving Space: Papers on Infant Observation. London: Karnac.

Canham, H. (1999) 'The Development of the Concept of Time in Fostered and Adoptive Children.' Psychoanalytic Inquiry 19 (2) 1999 160-171.

Canham, H. (2003) 'The relevance of the Oedipus myth to fostered and adopted children.' 29 (1) April 5-20.

Canham H. (2004) 'Spitting, kicking and stripping: technical difficulties encountered in the treatment of deprived children.' Journal of Child Psychotherapy 30 (2) August 2004 143-154.

will certainly be useful, but will they be teaching psychoanalytic psychotherapists much that they do not already know? 
Fonagy, P. (2001) Attachment Theory and Psychoanalysis. New York: Other Press.

Fraiburg, S. , Adelson, E., and Shapiro, V. (1975) 'Ghosts in the nursery: a psychoanalytic approach to the problems of impaired infant-mother relationships.' Journal of the American Academy of Sciences, 14: 387-422..

Galison, P. \& Stump, D.J. (ed) (1996). The Disunity of Science. Stanford: Stanford University Press.

Haag, G. (2000) 'In the footsteps of Frances Tustin: further reflections in the construction of the body ego.' International Journal of Infant Observation 3 (3) 7-22.

Hall, A. (2003/4) 'Trauma and containment in children's cancer treatment' . International Journal of Infant Observation 6 (2) 111-127.

Hindle, D. (2000) 'Assessing Children's Perspectives on Sibling Placements in Foster or Adoptive Homes,' Clinical Child Psychology and Psychiatry, 5(4), pp. $613-625$.

Hodges, J.(1999) 'Research in child and adolescent psychotherapy: an overview,', in Lanyado M. and Horne, A. (1999) The Handbook of Child and Adolescent Psychotherapy. London: Routledge.

Hopkins, J. 'Overcoming a child's resistance to late adoption: how one new attachment can facilitate another.' Journal of Child Psychotherapy 26 (3) December 2000, 335-347.

Houzel, D. (1995) 'Precipitation Anxiety'. Journal of Child Psychotherapy, 21 (1) $65-78$.

Houzel, D. (2004 'The psychoanalysis of infantile autism.' Journal of Child Psychotherapy 30 (2) August 225-237.

Hughes, J.M. (2004) From Obstacle to Ally: the Making of Psychoanalytic Practice. Hove: Brunner-Routledge.

Hunter, M. (2001) Psychotherapy with Young People in Care: Lost and Found. London: Brunner-Routledge.

Ironside, L. (1995) 'Beyond the Boundaries: a patient, a therapist and an accusation of sexual abuse.' Journal of Child Psychotherapy 21 (2) 183-206.

Joseph, B. (1989) Psychic Equilibrium and Psychic Change: Selected Papers of Betty Joseph. London: Routledge/Institute of Psychoanalysis.

Joseph, B. (1998) 'Thinking about a playroom. Journal of Child Psychotherapy 24 (3) December 359-366. 
Kenrick, J. (2005) 'Where we live: some dilemmas and technical issues for the child psychotherapist in interpretative work with looked-after and adopted children.' Journal of Child Psychotherapy 31 (1) April 24-39.

King, P. and Steiner, R. (1991). The Freud-Klein Controversies 1941-45. London: Routledge / Institute of Psychoanalysis.

Klein, S. (1980) 'Autistic phenomena in neurotic states,' International Journal of Psycho-Analysis 61: 395-402.

Kuhn, T.S. (1962) The Structure of Scientific Revolutions. Chicago: Chicago University Press.

Kuhn, T.S. (2000) The Road Since Structure: Philosophical Essays 19701990 with an autobiographical interview. Ed. James Conant and John Haugeland. London: University of Chicago.

Lanyado, M. (1991) 'Putting theory into practice: struggling with perversion and chaos in the analytic process.' Journal of Child Psychotherapy 17 (1) 2540 .

Latour, B. (1983) 'Give me a Laboratory and I will Raise the World,' in KnorrCetina, K., \& Mulkay, M. (eds) Science Observed. London: Sage.

Latour, B. (1987. Science in Action : how to follow scientists and engineers through society. Milton Keynes : Open University Press.

Latour, B. ( 1988) The Pasteurisation of France. London: Harvard University Press.

Lanyado, M. and Horne, A. (ed) 1999 The Handbook of Child and Adolescent Psychotherapy. London: Routledge.

Maiello, S. (1995) 'The sound-object: a hypothesis about pre-natal auditory experience and memory.' Journal of Child Psychotherapy 21 (2) 23-42.

McLeod, J. (2001) Qualitative Research in Psychotherapy and Counselling. London: Sage.

Meltzer, D. (1967) The Psycho-Analytical Process. London: Heinemann. .

Meltzer, D. (1978) The Kleinian Development. Perthshire Clunie Press.

Meltzer, D. , Bremner, D., Hoxter S., Weddell D., Wittenberg I. (1975)

Explorations in Autism: a Psychoanalytical Study. Perthshire: Clunie Press. 
Midgley, N. (2004) 'Sailing between Scylla and Charybdis; incorporating qualitative approaches into child psychotherapy research.' Journal of Child Psychotherapy 30 (1) April 89-111.

Midgley, N. (2006) 'The inseparable bond between cure and research': clinical case study as a method of psychoanalytic inquiry.' Journal of Child Psychotherapy 32 (2) August 122-147.

Ogden, T., (1989) The Primitive Edge of Experience. New York: Jason Aronson.

Philps, J. (2003) 'Applications of Child Psychotherapy to Work with Children in Temporary Foster Care.' Unpublished D. Psych. Psych. Thesis, University of East London.

Polanyi, M. (1958) Personal Knowledge: Towards a Post-Critical Philosophy. London: Routledge and Kegan Paul.

Rhode, M. (1994) 'Autistic breathing,' Journal of Child Psychotherapy 20 (1) 25-42.

Rhode, M. (2004) 'Different responses to trauma in two children with autistic spectrum disorder: the mouth as crossroads for the sense of self.' Journal of Child Psychotherapy 30 (1) December 3-20.

Rhode, M. and Klauber, T. (ed) (2004) The Many Faces of Aspberger's Syndrome. London: Karnac.

Rosenfeld, S.K. and Sprince, M.P. (1963). 'An Attempt to Formulate the Meaning of the Concept "Borderline"' Psychoanalytic Study of the Child 18. 603-635.

Rustin, M.E. (1991) 'The strengths of a practitioner's workshop as a new model in clinical research,' in S. Miller and R. Szur (eds) Extending Horizons London: Karnac.

Rustin, M.E. (1999) 'Multiple Families in Mind' Clinical Child Psychology and Psychiatry 4 (1) January.

Rustin, M.E. (2001) 'The Therapist with her Back against the Wall.' Journal of Child Psychotherapy 27 (3) December 273-285

Rustin, M.E. (2005) Conceptual analysis of critical moments in Victoria Climbié's life'. Child \& Family Social Work, 10 (1) February 11-19.

Rustin, M.E. , Rhode, M., Dubinsky, A., Dubinsky, H. (eds) (1997) Psychotic States in Children. London: Karnac.

Rustin, M.J. (1997/2002a) 'Give me a consulting room... The generation of psychoanalytic knowledge', (British Journal of Psychotherapy 13 (4) 527-541 
July 1997) rev. in Reason and Unreason: Psychoanalysis, Science, Politics. London: Continuum Books.

Rustin, M.J. (2002b) 'Looking in the Right Place: Complexity Theory, Psychoanalysis and Infant Observation', The International Journal of Infant Observation, 5, 1, (Spring) 122-144.

Rustin, M.J. (2003) 'Learning about Emotions: the Tavistock Approach', European Journal of Psychotherapy, Counselling and Health', 6 (3) 187-208.

Rustin, M.J. (2007) 'How do pychoanalysts know what they know?' in The Academic Face of Psychoanalysis, edited by Louise Braddock and Michael Lacewing. London: Routledge.

Sandler, J. (1988) 'The concept of projective identification,' in Sandler, J. (ed) Projection, Identification and Projective Identification. New York: International Universities Press.

Sorensen, P. (2000) 'Observations of transition facilitating behaviour development and theoretical implications' International Journal of Infant Observation 3 (2) 46-54.

Stove, D. (1982) Popper and After: Four Modern Irrationalists. Oxford: Pergamon Press.

Trowell, J., Rhode, M., Miles, G., Sherwood, I. Childhood depression: Work in progress. (2003) Journal of Child Psychotherapy 29 (2) August 147-169.

Tuckett, D. (1994) 'Developing a grounded hypothesis to understand a clinical process: the role of conceptualisation in validation.' International Journal of Psychoanalysis 75 (5/6).

Tuckett, D. (ed) (1994) Anniversary Issue of International Journal of Psychoanalysis on Clinical Facts, 75 (5/6).

Tustin, F. (1992) Autistic States in Children. (revised ed.) London: Routledge.

Tustin, F. (1994) 'The Perpetuation of an Error', Journal of Child Psychotherapy 20 (1) April 3-24.

Williams, G. (previously Henry G.) 'Doubly Deprived'. Journal of Child Psychotherapy 3 (4) December 1974 15-28.

Williams, G. (1997) Internal Landscapes and Foreign Bodies: Eating Disorders and Other Pathologies. London Duckworth 
Williams, G.. Williams, P., Desmarais, J. Ravenscroft, K. (eds) The Generosity of Acceptance. Vol 2 Exploring Feeding Difficulties in Adolescents. London: Karnac 